patients with a thrombus above the popliteal who are at risk, and it is in them that anticoagulant therapy is particularly important. This extension of the thrombus can be easily detected with the Pitman model 235 isotope localization monitor, and treatment can be instituted at the proper time.

We are grateful to the physicians of King's College Hospital who allowed us to study patients under their care; to Professor J. G. Murray and Dr. S. Oram for their advice; to Pfizer Ltd. (U.K.) for financing a research fellowship for J.T.G.R.; to the King's College Hospital Research Fund for financial assistance to A.N.N.; and to Mr. S. Serunkuma for invaluable technical help.

\section{References}

Atkins, P., and Hawkins, L. A. (1965). Lancet, 2, 1217.

Browder, F. S., Pérez Olea, J. O., and de Francisco, A. (1959). Archivos de Instituto de Cardiología de México, 29, 31.
Flanc, C., Kakkar, V. V., and Clarke, M. B. (1968). British fournal of Surgery, 55, 742

Hilden, T., Iversen, K., Raaschou, F., and Schwartz, M. (1961). Lancet, 2, 327 .

Kakkar, V. V. (1971). American Heart fournal. In press.

Kakkar, V. V., Howe, C. T., Flanc, C., and Clarke, M. B. (1969). Lancet, 2,230

Kakkar, V. V., Howe, C. T., Nicolaides, A. N., Renney, J. T. G., and Clarke, M. B. (1970a). American fournal of Surgery, 120, 527

Kakkar, V. V., Nicolaides, A. N., Renney, J. T. G., Friend, J. R., and Clarke, M. B. (1970b). Lancet, 1, 540.

Kucera, M. (1966). Vnitrni Lékarstvi, 12, 209.

Kucera, M. (1966). V nitrni Lekarstvi, 12, 209.

Lown, B., Kosowsky, B. D., and Klein, M. D. (1969). Circulation, Suppl. No. 4, p. 261. McFarlane, A. S. (1963). Fournal of Clinical Investigation, 42, 346 .

Medical Research Council, Report of the Working Party on Anticoagulant Therapy in Coronary Thrombosis (1969). British Medical Fournal, 1, 335.

Murray, T. S., Lorimer, A. R., Cox, F. C., and Lawrie, T. D. V. (1970) Lancet, 2, 792.

Negus, D., Pinto, D. J., Le Quesne, L. P., Brown, N., and Chapman, M. (1968). British Fournal of Surgery, 55, 835

Nicolaides, A. N. (1970). Unpublished data.

\title{
Termination of Pregnancy with Intra-amniotic Hypertonic Saline
}

\author{
M. D. G. GILLMER, J. R. FRIEND, R. W. BEARD
}

British Medical fournal, 1971, 1, 434-437

\section{Summary}

Successful therapeutic abortion was performed consecutively by an intra-amniotic injection of hypertonic saline in 102 out of 110 patients in whom the size of the uterus corresponded with a pregnancy of 16 weeks or more.

A spontaneous abortion of the fetus followed the injection alone in 92 of the cases, and the overall injection-delivery interval was 39.75 (range 11-98) hours. In 10 women intravenous oxytocin injection was used as an additional uterine stimulant because contractions were not established after 48 hours. Complete spontaneous expulsion of the placenta occurred in 71 cases, and evacuation of the placenta under general anaesthesia was required in the other 31 .

No major complication occurred among the 110 patients.

\section{Introduction}

With the increase in the number of legal abortions performed in National Health Service hospitals since the passage of the Abortion Act in 1967, termination of pregnancy by the intraamniotic injection of hypertonic saline has been used with increasing frequency, particularly as an alternative to hysterotomy. The technique, originally described by Aburel (1934), has been widely used in Scandinavia to induce midtrimester abortions (Wagner et al., 1962) and to investigate the mechanism of onset of labour (Bengtsson and Csapo, 1962). In Britain the use of both hypertonic glucose and hypertonic saline in cases of missed abortion or intrauterine death has been

Queen Charlotte's Maternity Hospital, London W.6

M. D. G. GILLMER, M.B., B.s., Senior House Officer

Department of Obstetrics and Gynaecolosy, King's College Hospital, London S.E.S

J. R. FRIEND, B.M., M.R.C.o.G., Senior Registrar

R. W. BEARD, M.D., M.R.C.o.G., Senior Lecturer reported (Wood et al., 1962; Millar and Harvey, 1966). Hypertonic saline, however, has not been popular because of the reports of several deaths following its use (Wagatsuma, 1965; Cameron and Dayan, 1966; Frost, 1968; Cameron et al., 1969).

This paper describes the experience from a consecutive series of 110 patients aborted by intra-amniotic hypertonic saline.

\section{Patients and Methods}

All the patients in this series were treated at King's College Hospital or Dulwich Hospital between March 1969 and February 1970. Therapeutic abortion had been agreed to under one or more sections of the Abortion Act of 1967. The main criteria influencing the decision to use this method were that the uterine size should be at least that of a pregnancy of 16 weeks' gestation and that the patient should have no medical condition complicating the pregnancy. The ages of the patients ranged from 15 to 45 years; 23 were under 19 years and 77 were 19 to 30 years. Eighty-four patients were of Caucasian origin and 26 were Negroid.

The intra-amniotic injection of saline was initially performed in the operating theatre, but later it became a routine procedure in the ward. The haemoglobin and blood group of all patients were determined beforehand. Intramuscular pethidine $75 \mathrm{mg}$ and promethazine $25 \mathrm{mg}$ was given one hour before the procedure and all patients were asked to void urine at this time. In those cases where it was not certain that the bladder had been fully emptied catheterization was performed. Vaginal examination was occasionally necessary to locate the uterus accurately in obese patients. In these cases it was found helpful to place a pillow under the patient's back to exaggerate the curve of the lumbar spine.

Strict aseptic precautions were used throughout. The site selected for abdominal puncture was infiltrated with $1 \%$ lignocaine. After this a 9-cm 16-gauge Tuohy needle was introduced direct through the abdominal wall into the uterus. In most cases entry of the needle into the uterine cavity was 
accompanied by a definite "give" and was confirmed by free reflux of clear amniotic fluid when the stylet was removed from the needle. The needle was fixed in position by Spencer Wells forceps the teeth of which were covered with rubber, and $100-200 \mathrm{ml}$ of amniotic fluid was withdrawn with a $50-\mathrm{ml}$ syringe. Then $18 \%$ saline solution was injected slowly into the uterine cavity. The correct position of the tip of the needle was confirmed by checking for spontaneous reflux of amniotic fluid after every $10 \mathrm{ml}$ of saline injected. If at any stage during the injection free reflux could not be obtained or if the fluid became bloodstained then the injection was stopped. Subsequent experience has shown that it is necessary to test for reflux only after every $50 \mathrm{ml}$ of saline injected.

Throughout the procedure the patient was awake so that side effects from intravascular or intraperitoneal injection could be detected. These are lower abdominal pain and a feeling of faintness or flushing, tingling, or burning of the face, upper limbs, or mouth. Our aim, where possible, was to inject a minimum of $100 \mathrm{ml}$ of saline and never more than $200 \mathrm{ml}$. To avoid the possibility of intrauterine infection 600 $\mathrm{mg}$ of benzylpenicillin and $500 \mathrm{mg}$ of streptomycin were added to the injected solution.

After completion of the injection the patient remained in bed for at least eight hours, during which regular blood pressure and pulse records were made. Then she was allowed up until the onset of painful contractions.

If contractions had not begun within 48 hours of the injection an intravenous infusion of oxytocin (Syntocinon) in $5 \%$ dextrose was started. The infusion regimen adopted involved a rapid increase in dosage of oxytocin up to a maximum of 100 units per pint (176 units per litre). The infusion was maintained for only $10-12$ hours at a time in order to avoid the complication of water intoxication (Roberts et al., 1970). Intramuscular ergometrine $0.5 \mathrm{mg}$ was given after the delivery of the fetus. When the placenta was retained no immediate action was taken, but the patient was kept in bed and a vaginal examination was performed 10-12 hours later. If the placenta was still in utero a manual removal under general anaesthetic was carried out. All patients were kept in hospital for $\mathbf{4 8}$ hours after the abortion, but subsequent experience has shown that provided the placenta is completely expelled the patient can be safely discharged 24 hours after the abortion.

\section{Results}

Abortion was successful in 102 out of 110 patients. In 58 no treatment other than the initial injection of hypertonic saline was necessary.

Injection-Delivery Interval.-The injection-delivery interval in the 102 successful cases ranged from 11 to 98 (mean 39.75) hours-(see Chart). Delivery of the fetus occurred before 48 hours in 77 patients and before 72 hours in 99 . There is no correlation between the injection-delivery interval and either the duration of pregnancy or the parity of the patient. The mean injection-delivery interval in primigravid patients was $41.1 \pm 15.5$ hours compared with $37.3 \pm 17.6$ hours in multiparous patients $(P>0.2)$.

Syntocinon Infusion.-Intravenous infusion of Syntocinon was used in 10 of the 25 cases where the injection-delivery interval was more than 48 hours. In the other 15 patients painful contractions were occurring 48 hours after the injection and spontaneous abortion resulted some hours later. The duration of the infusion ranged from 6 to 27 (mean 15.9)
hours.

Incomplete Abortion.-In 51 of the 102 successful abortions the time from the delivery of the fetus to the passage of an intact placenta was less than 30 minutes. In most cases delivery of the fetus was followed closely by expulsion of the

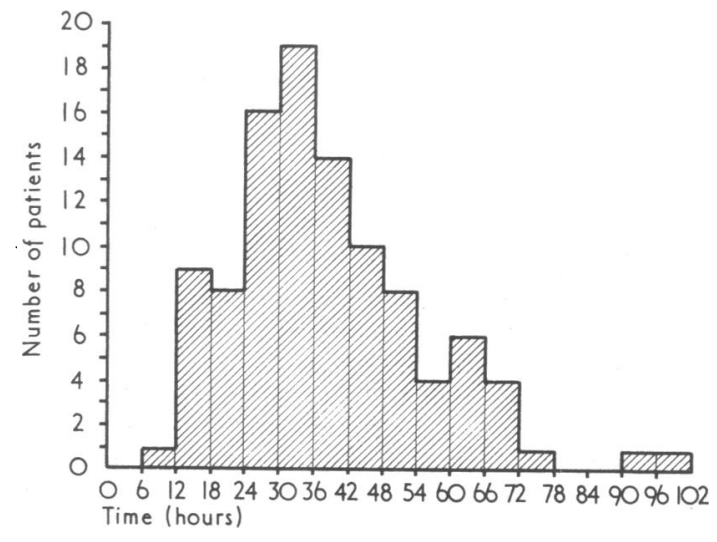

Injection-delivery interval in 102 cases.

placenta and membranes. In 20 the placenta delivered spontaneously from 30 minutes to 14 hours after the passage of the fetus (mean $5.3 \pm 4.2$ hours). Thirty-one patients required evacuation of the uterus under general anaesthesia-in 25 the complete placenta had been retained, while in 6 it was expelled incomplete. The incidence of retention of the whole or fragments of the placenta was lowest in terminations performed between the 16th and 19th weeks of pregnancy (see Table).

Incidence of Retained Products of Conception Related to Gestational Length of Pregnancy

\begin{tabular}{|c|c|c|c|c|c|}
\hline $\begin{array}{c}\text { Weeks of } \\
\text { Gestation } \\
\text { from } \\
\text { L.M.P. }\end{array}$ & $\begin{array}{l}\text { No. of } \\
\text { Cases }\end{array}$ & $\begin{array}{c}\text { No. } \\
\text { Requiring } \\
\text { Evacuation }\end{array}$ & $\begin{array}{l}\text { Weeks of } \\
\text { Gestation } \\
\text { from } \\
\text { L.M.P. }\end{array}$ & $\begin{array}{l}\text { No. of } \\
\text { Cases }\end{array}$ & $\begin{array}{c}\text { No. } \\
\text { Requiring } \\
\text { Evacuation }\end{array}$ \\
\hline \multirow[t]{2}{*}{$\begin{array}{l}12 \\
14 \\
15 \\
16 \\
17 \\
18\end{array}$} & \multirow[t]{2}{*}{$\begin{array}{r}1 \\
2 \\
7 \\
21 \\
25 \\
25\end{array}$} & \multirow[t]{2}{*}{$\begin{array}{l}1 \\
1 \\
4 \\
8 \\
6 \\
5\end{array}$} & $\begin{array}{l}19 \\
20 \\
21 \\
22 \\
23\end{array}$ & $\begin{array}{r}10 \\
5 \\
2 \\
3 \\
1\end{array}$ & $\begin{array}{l}1 \\
1 \\
1 \\
2 \\
1\end{array}$ \\
\hline & & & Total & 102 & 31 \\
\hline
\end{tabular}

Failed Technique.-In eight cases either the introduction of the needle or the injection was unsuccessful and the procedure was abandoned in favour of other techniques. These cases can be divided into three groups: (1) four cases in which no reflux of amniotic fluid could be obtained, (2) three cases in which only blood-stained amniotic fluid could be withdrawn, and (3) one case in which the patient experienced side effects. In two cases abortion was subsequently produced by intravenous infusion of prostaglandins and in the other six a hysterotomy was performed. An anterior placenta was found at operation in five of these cases, and in one the uterine size was found to correspond to only 12 weeks' gestation. Later in the series it was found on two occasions that where only blood could be aspirated through a 9-cm Tuohy needle penetration of the amniotic sac was successfully achieved with a $15-\mathrm{cm}$ needle. Thus it is possible that three of the hysterotomies on patients in group 1 could have been avoided.

Side Effects and Complications.-In the patient who complained of lower abdominal pain and a generalized sensation of flushing after the injection of only $25 \mathrm{ml}$ of hypertonic saline the procedure was abandoned, and no further side effects were observed. Four patients vomited soon after injection of the saline. Thirst (usually lasting 12 to 15 hours) was a common complaint. A low-grade pyrexia (less than $38^{\circ} \mathrm{C}$ ) appeared after abortion in four patients. Four lost more than a pint $(570 \mathrm{ml})$ of blood and each was transfused with whole blood. All had had an evacuation of retained products under general anaesthesia. 


\section{Discussion}

Our experience suggests that the routine use of intra-amniotic hypertonic saline is a safe and effective method for inducing abortion after the 15th week of pregnancy. In the past the use of saline for termination of pregnancy has fallen into disrepute because of several reports of death. Where sufficient details are given most of these deaths appear to have been associated with a faulty technique.

No definitive work seems to have been done on the maximum dose of saline which can be safely injected, but it is generally agreed that about $200 \mathrm{ml}$ of $20 \%$ saline $(40 \mathrm{~g}$ of sodium chloride) is the upper limit for therapeutic abortion. Several workers have investigated the electrolyte changes in amniotic fluid, serum, and urine after injection of hypertonic saline. Anderson and Turnbull (1968), using $200 \mathrm{ml}$ of $20 \%$ saline, found that there is a fairly rapid decline in amniotic fluid sodium concentration from the initial level (about 2,500 $\mathrm{mEq} / \mathrm{l}$.) to about $500 \mathrm{mEq} / \mathrm{l}$. after 12 hours. There is a simultaneous rise in serum sodium of about $10 \mathrm{mEq} / \mathrm{l}$. and hence of serum osmolality, which apears to induce a temporary antidiuresis. As serum sodium and osmolality fall, urinary excretion of sodium increases and it is found that about 60$70 \%$ of the initial salt load is excreted by the time of abortion. It appears, therefore, that a healthy woman can easily handle $40 \mathrm{~g}$ of sodium chloride administered in this way. Our results suggest that the optimal dose of hypertonic saline for injection is $150 \mathrm{ml}$ of an $18 \%$ solution ( $27 \mathrm{~g}$ of sodium chloride, which is unlikely to have any adverse effects in healthy women). The danger of using an excessive amount of saline is illustrated in one of the fatal cases described by Cameron and Dayan (1966) in which $400 \mathrm{ml}$ of $20 \%$ saline was injected into the amniotic sac.

Faulty technique remains a hazard even when the total amount of saline injected is well within "normal" limits. Johnson et al. (1966) demonstrated in dogs that comparatively small volumes of hypertonic saline injected intravenously can produce rapid death, and for this reason it is imperative to make sure that amniotic fluid can be aspirated at all times during the procedure. If this precaution had been observed in the case of injection into a hydatidiform mole described by Frost (1968) the patient might not have died. Heavily bloodstained amniotic fluid is always a contraindication to continuing with the injection because of the increased risk of intravascular injection. Goodlin et al. (1969) reported five such patients who developed early symptoms of hypernatraemia and in whom the procedure had to be abandoned. Peritoneal spill of large amounts of hypertonic saline may be fatal, probably because of rapid absorption (Cameron et al., 1969), so it is important to limit the number of attempts at amniocentesis. Cameron and Dayan (1966), describing a death, noted that multiple puncture sites were found in the uterus at necropsy. This patient was anaesthetized when the saline was injected-which underlines the importance of carrying out the procedure in the fully conscious patient so that intravascular injection or peritoneal spill can be recognized immediately.

The selection of patients is important. The retrospective report on the mortality following the use of hypertonic saline in postwar Japan by Wagatsuma (1965) is often quoted as a strong argument against its use for inducing abortion. The paper suggests that many of the deaths had avoidable factors. In an unspecified number of cases abortion was performed by non-specialist personnel in inadequately equipped institutions. Furthermore, several of the 25 patients who died were in poor health at the time of abortion. Though successful induction of abortion in patients with chronic renal disease and fulminating pre-eclampsia has been reported (Menzies and Hawkins, 1968; Goodlin et al., 1969) the use of this technique in patients with these conditions is best avoided. Pathak (1968) described oliguria as a complication of the use of hypertonic saline in a woman with severe hvpertension.

Several authors advocate the routine administration of an oxytocic infusion immediately after the saline has been injected. We felt that oxytocin should be used only if the patient showed no evidence of established uterine activity after 48 hours. Wagner et al. (1962) failed to find any significant diminution of the injection-delivery interval by the routine use of oxytocin when contractions had not started within 24 hours. Our results tend to support this view as $91 \%$ of patients aborted spontaneously. In addition, the risk of water intoxication (Goodlin et al., 1969), which may result from the infusion of a large quantity of water together with the antidiuretic effect of high doses of oxytocin, is avoided.

Intrauterine infection is an occasional complication of the procedure. The incidence of a low-grade pyrexia following abortion was 16 and $9 \%$ respectively in the series reported by Menzies and Hawkins (1968) and Goodlin et al. (1969). In our series a significant pyrexia occurred in only $3 \%$ of patients. This low incidence may well be due to the addition of broad-spectrum antibiotics to the saline.

Few authors describe a definite policy for dealing with the retained placenta. It is often considered wise to proceed immediately to evacuation because of the potential risks of haemorrhage and infection associated with prolonged retention of the placenta. We, however, found that in most cases the placenta was delivered spontaneously within 10-12 hours from the time of the abortion of the fetus, there being no case of uterine haemorrhage or subsequent infection as a consequence of this delay. In fact it is likely that if the full 12hour period had been allowed to elapse in all our patients the total number of evacuations could have been reduced even further.

Termination of pregnancy by any method carries a potential risk of sensitization of a rhesus-negative mother because of feto-maternal haemorrhage. Walsh and Lewis (1970) found that intra-amniotic injection of hypertonic solution was associated with a low'er incidence of significant feto-maternal haemorrhage than most other techniques used for termination. Their conclusions, however, are of limited significance because they used the Kleihauer method for estimating the number of fetal cells in the maternal circulation.

The use of intra-amniotic hypertonic saline for termination of pregnancy has several practical advantages. Permanent damage to the cervix which may occur after vacuum aspiration or curettage is minimized. The technique has much to offer in the primigravid patient whose pregnancy has advanced beyond 12 weeks' gestation. A potentially hazardous vaginal operation can be avoided and the need to admit the patient urgently before the uterus is too large is eliminated. Thus hypertonic saline is a preferable alternative to hysterotomy, avoiding the risks of a laparotomy and the resulting uterine scar and reducing the length of stay in hospital. The instillation of the saline and the abortion take place in the ward, thus relieving the load on routine operating lists.

The mean injection-delivery time after hypertonic saline was 39.75 hours, and though the mean inpatient stay was five days, experience subsequent to our study has shown that this period can be reduced by carrying out the procedure shortly after the patient is admitted to hospital and, because of the low incidence of complications, by earlier discharge after completion of the abortion.

There is little doubt that provided simple precautions are taken hypertonic saline is a useful abortifacient. It is important to stress, however, that the procedure is acceptable for clinical use only if constant attention is paid to technique. If at any time there is doubt about whether the tip of the needle is lying in the amniotic cavity or if the patient complains of any of the recognized side effects then the procedure should be abandoned. Likewise, if the uterus is too small the procedure should be delaved until it is easily palpable per abdomen.

It is recognized that even a careful technique cannot completely overcome the dangers of hypertonic saline and it 
is hoped that in the future a solution which is as effective as saline, but which can be injected intravenously or intraperitoneally without danger to the patient, will be found.

We wish to thank Professor S. G. Clayton, Mr. J. M. Brudenell, and $\mathrm{Mr}$. R. M. Feroze for their encouragement and for allowing us to include their patients in this series. We are also grateful to the medical and nursing staff of $\mathrm{H}_{2}$ Ward, Dulwich Hospital, and Fergusson Ward, King's College Hospital, for their kind help and co-operation.

Requests for reprints should be sent to Dr. J. R. Friend.

\section{References}

Aburel, E. (1934). Communicare la Sociecatea Stiintelor Medicale, Iasi. Anderson, A. B. M., and Turnbull, A. C. (1968). Acta Obstetricia et Gynecologica Scandinavica, 47, 1.

Bengtsson, L. P., and Csapo, A. I. (1962). American fournal of Obstetrics and Gynecology, 83, 1083.

Cameron, J. M., and Dayan, A. D. (1966). British Medical fournal, 1, 1010.
Cameron, J. M., Morgan, A. G., Robinson, A. E., and Urich, H. (1969), Fournal of Obstetrics and Gynaecology of the British Commonwealth, 76. 168. Frost, A. C. G. (1968). American fournal of Obstetrics and Gynecology, 101,

Goodlin, R. C., McLennan, C. E., Choyce, J. M., Lee, R. S., and Stickler, J. E. (1969). Obstetrics and Gynecology, 34, 1.

Johnson, J. W. C., Cushner, I. M., and Stephens, N. L. (1966). American Fournal of Obstetrics and Gynecology, 94, 225.

Menzies, D. N., and Hawkins, D. F. (1968). Fournal of Obstetrics and Gynaecology of the British Commonwealth, 75, 215.

Millar, D. R., and Harvey, L. P. (1966). British Medical fournal, 1, 327

Pathak, V. N. (1968). American fournal of Obstetrics and Gynecology, 101, 513.

Roberts, G., Andersen, A., McGarry, J., and Turnbull, A. C. (1970). British Medical fournal, 2, 152

Wagatsuma, T. (1965). Ámerican fournal of Obstetrics and Gynecology, 93, 743.

Wagner, G., Karker, H., Fuchs, F., and Bengtsson, L. P. (1962). Danish Medical Bulletin, 9, 137.

Walsh, J. J., and Lewis, B. V. (1970). Fournal of Obstetrics and Gynaecology of the British Commonwealth, 77, 133.

Wood, C., Booth, R. T., and Pinkerton, J. H. M. (1962). British Medical Fournal, 2, 706 .

\title{
Effect of Frusemide Administration on Calcium Excretion
}

\author{
H. TOFT, J. ROIN
}

British Medical fournal, 1971, 1, 437-438

\section{Summary}

Each of eight adipose but otherwise normal patients on a reducing diet received daily oral doses of frusemide for four days; the degree of hypercalciuria was found to be significant during the first three days, but on day four the calcium excretion in the urine had become normal though frusemide was still being given. The rates of excretion of sodium and calcium in the urine were closely correlated.

\section{Introduction}

Thiazide diuretics are known to reduce the excretion of calcium in the urine (Lamberg and Kuhlbäck, 1959), and these drugs have been used in the treatment of idiopathic hypercalciuria (Yendt, Gagne, and Cohanim, 1966). Tambyah and Lim (1969) found a significant increase in the urine excretion of calcium throughout an eight-hour interval after oral administration of a single dose of $80 \mathrm{mg}$ frusemide. They suggested that frusemide might be of value in the treatment of hypercalcaemia provoked by malignant diseases. As we have observed the development of hypocalcaemia in a patient with cardiac insufficiency treated with frusemide (Toft and Roin, 1971) we found it of interest to examine the effect of continuous frusemide therapy on the daily excretion of calcium in normal subjects, because this aspect had apparently not been studied.

\footnotetext{
Department of Medicine $M$, University Clinic in Odense, 5000 Odense,
Denmark

H. TOFT, M.B. (Present address: Department of Medicine B, Glostrup

J. ROIN, M.B. (Present address: Department of Medicine, Lemvig ROIN, M.B. (Present address:
Hospital, 7620 Lemvig, Denmark)
}

\section{Patients and Methods}

Eight adipose but otherwise normal patients took part in the experiment. Urine was collected on seven consecutive days, beginning at 8 a.m. and ending at 8 a.m. On days $4,5,6$, and 7 oral doses of $80 \mathrm{mg}$ of frusemide were given at 8 a.m. The calcium level in serum was determined on the first and seventh days at 12 noon. Levels of calcium in serum and urine and the level of sodium in the urine were determined by spectrophotometry. The patients were on reducing diets but had free access to fluid intake. The calcium content of the diets was estimated at less than $800 \mathrm{mg}$ daily.

\section{Results}

The effect of frusemide on the daily excretion of calcium in the urine is shown in the Table. Rates of excretion did not deviate significantly during the three 24-hour control periods. The types of deviation to be expected because of the variations observed during the control period of three days were analysed, and on the basis of this analysis the excretion of calcium during treatment was calculated. The excretion of calcium was found to be increased during the first, second, and

Excretion of Calcium in Urine before and during Treatment with Daily Doses of $80 \mathrm{mg}$ of Frusemide

\begin{tabular}{|c|c|c|c|c|c|c|c|c|}
\hline \multirow{4}{*}{$\begin{array}{l}\text { Case } \\
\text { No. }\end{array}$} & \multicolumn{8}{|c|}{ Total 24 hour Excretion of Calcium in Urine (mg) } \\
\hline & \multicolumn{4}{|c|}{ No Frusemide (Control) } & \multirow{2}{*}{\multicolumn{4}{|c|}{$\begin{array}{c}\text { During Frusemide Therapy } \\
\text { Periods of } 24 \text { Hours }\end{array}$}} \\
\hline & \multicolumn{3}{|c|}{ Periods of 24 Hours } & \multirow{2}{*}{$\begin{array}{c}\text { Average of } \\
\text { Periods } \\
1,2,3\end{array}$} & & & & \\
\hline & 1st & 2nd & 3 rd & & 4th & 5 th & 6th & 7th \\
\hline $\begin{array}{l}\cdots \\
\cdots \\
\cdots \\
\cdots \\
\cdots\end{array}$ & $\begin{array}{l}223 \\
162 \\
142 \\
179 \\
191 \\
279 \\
278 \\
139\end{array}$ & $\begin{array}{l}181 \\
179 \\
168 \\
180 \\
183 \\
335 \\
279 \\
133\end{array}$ & $\begin{array}{l}175 \\
179 \\
113 \\
204 \\
237 \\
305 \\
275 \\
157\end{array}$ & $\begin{array}{l}193 \\
173 \\
141 \\
188 \\
204 \\
306 \\
277 \\
143\end{array}$ & $\begin{array}{l}225 \\
230^{*} \\
223 \ddagger \\
240^{*} \\
237 \\
338 \\
298 \\
249 \ddagger\end{array}$ & $\begin{array}{l}204 \\
285 \ddagger \\
144 \\
172 \\
220 \\
304 \\
292 \\
229 \dagger\end{array}$ & $\begin{array}{l}209 \\
290 \ddagger \\
102 \\
204 \\
232 \\
293 \\
244 \\
211\end{array}$ & $\begin{array}{l}211 \\
223 \\
122 \\
195 \\
133 t \\
264 \\
205 t \\
184\end{array}$ \\
\hline \multirow{2}{*}{$\begin{array}{l}\text { Mean } \\
\text { Standard } \\
\text { deviation }\end{array}$} & $199 \cdot 1$ & $204 \cdot 8$ & $205 \cdot 6$ & $203 \cdot 1$ & $255 \ddagger$ & $231 \cdot 3+$ & $223 \cdot 1^{*}$ & $192 \cdot 1$ \\
\hline & 55.9 & $66 \cdot 9$ & $63 \cdot 5$ & $59 \cdot 5$ & $41 \cdot 2$ & $58 \cdot 4$ & $60 \cdot 0$ & $46 \cdot 5$ \\
\hline
\end{tabular}

Deviations from the mean figure obtained during the control period are calculated $(t$ test) on the basis of the daily variations during the control period.
$* \mathrm{P}<0.05$. $\quad+\mathrm{P}<0.01$. $¥ \mathrm{P}<0.001$. 